Ambiente \& Água - An Interdisciplinary Journal of Applied Science
ISSN 1980-993X - doi:10.4136/1980-993X
www.ambi-agua.net
E-mail: ambi.agua@gmail.com

\title{
Atividades de lactato desidrogenase e malato desidrogenase de Astyanax bimaculatus (lambari) da bacia hidrográfica do rio Una como biomarcadoras de impacto ambiental
}

\author{
doi:10.4136/ambi-agua.1615
}

Received: 03 Mar. 2015; Accepted: 01 Jul. 2015

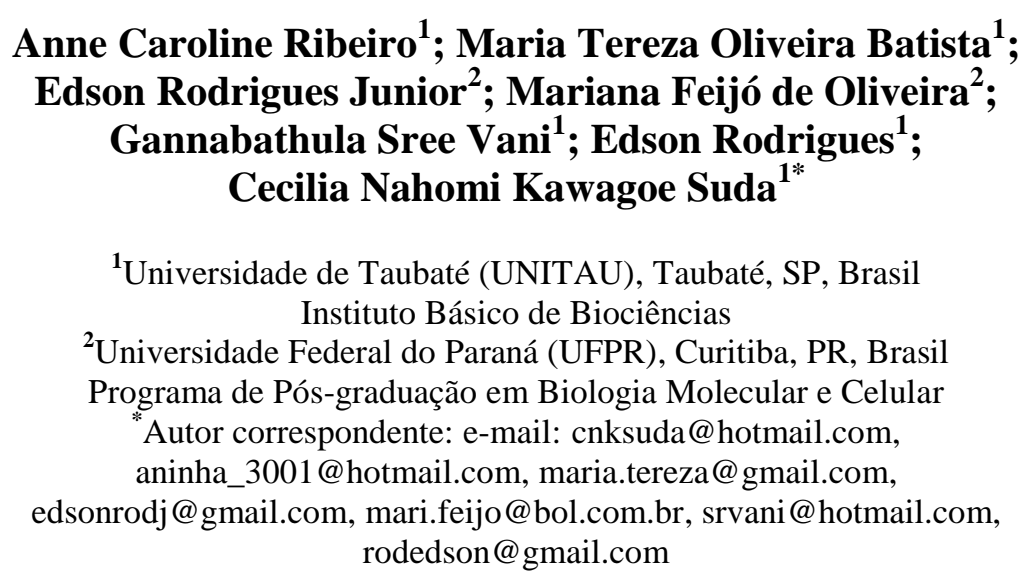

\section{RESUMO}

Os peixes vivem todo o ciclo de vida na água e recebem a influência dos seus componentes físico-químicos e biológicos ao longo do tempo. As atividades de lactato desidrogenase (LDH) e malato desidrogenase (MDH) de organismos aquáticos podem ser alteradas devido à presença de poluentes na água. $\mathrm{O}$ objetivo deste estudo foi determinar se as atividades de LDH e MDH nas brânquias e no fígado de Astyanax bimaculatus (lambari do rabo amarelo) podem ser utilizadas como biomarcadoras do impacto ambiental na bacia hidrográfica do rio Una (SP). Para isso, esses lambaris foram coletados em três corpos d'água dessa bacia, denominados p1 (rio Itaim), p2 (córrego à beira da Estrada Municipal de Remédios) e p3 (lago na Estrada Municipal Dr. José Luiz Cembranelli). As brânquias e o fígado foram homogeneizados e, a seguir, esse material foi centrifugado e o sobrenadante foi utilizado para determinação das atividades de $\mathrm{LDH}$ e $\mathrm{MDH}$, através do método espectrofotométrico que determina a taxa de oxidação de NADH. As atividades de LDH e $\mathrm{MDH}$ no fígado e de $\mathrm{MDH}$ branquial não foram estatisticamente diferentes nos lambaris coletados nos três locais. No tecido branquial a atividade de LDH foi inferior nos peixes de p3 em relação aos de p1. Essa inibição da atividade de $\mathrm{LDH}$, bem como a qualidade inferior da água nesse ponto, sugerem a ocorrência de poluentes nessa água. Conclui-se que LDH branquial de lambari possui potencial para utilização como marcador bioquímico de impacto ambiental no rio Una.

Palavras-chave: biomonitoramento, enzimas, poluição. 


\title{
Lactate dehydrogenase and malate dehydrogenase of Astyanax bimaculatus (lambari) from Una River basin as biomarkers of environmental impact
}

\begin{abstract}
Fish spend their whole life cycle in water and receive the influence of its physico-chemical and biological components over time. The activities of lactate dehydrogenase (LDH) and malate dehydrogenase (MDH) of aquatic organisms can be altered by pollutants in the water. The aim of this study was to determine whether the activities of LDH and MDH in the gills and liver of Astyanax bimaculatus (lambari do rabo amarelo or Two Spots Astyanax in English), can be used as biomarkers of environmental impact in the Una River (SP) Basin. The lambaris for these studies were collected from three water bodies of this basin designated as p1 (Itaim River), p2 (stream by the road to the Municipality of Remédios) and p3 (lake on the road to the Municipality of Dr. José Luiz Cembranelli). The gills and liver were homogenized and this material was then centrifuged and the supernatant was used for LDH and MDH activity assays using the spectrophotometric method, which determined oxidation rate of NADH. The activities of hepatic LDH and MDH and gill MDH were not statistically different in the lambaris collected at the three sites. In the gill tissue, LDH activity of lambaris from $\mathrm{p} 3$ was lower than that from p1.This inhibition of LDH in lambaris from p3, as well as the inferior quality of water there, suggest the occurrence of pollutants in this water. It is concluded that the $\mathrm{LDH}$ of lambari gills has potential for use as a biochemical marker of environmental impact in the Una River.
\end{abstract}

Keywords: biomonitoring, enzymes, pollution.

\section{INTRODUÇÃO}

A necessidade de se detectar e determinar o impacto dos poluentes sobre os organismos aquáticos levou ao estudo dos marcadores bioquímicos e moleculares (Slatinská et al., 2008). Esses são moléculas cuja presença ou a sua atividade podem ser quantificadas em fluidos corporais, células ou tecidos indicando modificações celulares adversas devido à presença de agentes tóxicos no meio ambiente (Pauwels et al., 2013). Uma detecção precoce do efeito sub-letal pode ser essencial para se decidir sobre a descontaminação do local poluído antes que modificações drásticas, como extinção de espécies nativas, ocorram no ecossistema em questão (Slatinská et al., 2008). Diversas enzimas têm sido investigadas quanto ao seu potencial como biomarcadoras, incluindo aquelas do metabolismo de xenobióticos, da defesa antioxidante e do metabolismo energético (Sedeño-Díaz e López-López, 2012). Lactato desidrogenase (LDH) e malato desidrogenase (MDH) são enzimas do metabolismo energético, e têm sido também investigadas em peixes, como biomarcadoras do impacto causado pela presença de pesticidas na água (Gorbatiuk, 2013) e de metais (Venugopal e Reddy, 1992; Reddy, 2012).

LDH (EC 1.1.1.27) catalisa a conversão reversível do lactato a piruvato numa reação de oxidorredução, na presença da coenzima $\mathrm{NAD}^{+}$, que atua como aceptor de hidrogênio, podendo doá-lo subsequentemente. LDH é responsável pela reoxidação de NADH durante a oxidação anaeróbia da glicose, portanto, é considerada uma indicadora da capacidade anaeróbica da célula. Em vertebrados, a enzima pode ser encontrada no músculo e é importante na capacidade de alguns peixes em produzir explosões repentinas de natação (Almeida et al., 2002). A atividade de LDH é um parâmetro amplamente utilizado em 
toxicologia e química clínica para diagnosticar danos em células, tecidos e órgãos (Diamantino et al., 2001).

MDH (EC 1.1.1.37) é uma enzima ativa durante o processo de respiração celular, regenerando uma molécula de oxalacetato a partir da oxidação de uma molécula de malato e utilizando $\mathrm{NAD}^{+}$como aceptor de elétrons. MDH pode ser citosólica ou mitocondrial, sendo a primeira importante na gliconeogênese, lipogênese e na lançadeira de malato aspartato. A segunda atua no ciclo de Krebs (Basaglia, 1989).

As águas do rio Una (Taubaté, SP) são utilizadas para o abastecimento público dos municípios de Taubaté e Tremembé. O rio e seus afluentes constituem a bacia hidrográfica do rio Una. Essa, por sua vez, é uma sub-bacia da bacia do rio Paraíba do Sul (Banco de Dados Ambientais da Bacia do Rio Una - http://www.agro.unitau.br/una). O monitoramento da qualidade das águas do rio Una tem sido realizado pela Companhia Ambiental do Estado de São Paulo (CETESB), somente no ponto de captação para abastecimento (2301'49" S; 45 30'26" O) da Companhia de Saneamento Básico do Estado de São Paulo (SABESP) (https://servicos.cetesb.sp.gov. br/infoaguas/). Não se tem notícias de monitoramento nos demais locais dentro da bacia e provavelmente isso não tem sido realizado regularmente.

Astyanax bimaculatus é um peixe de água doce mais conhecido como lambari do rabo amarelo (Hayashi et al., 2004). Essa espécie está presente nas águas da bacia hidrográfica do rio Una e as alterações nas atividades de suas enzimas, tais como LDH e MDH, podem indicar presença de contaminantes, mesmo em níveis subletais, e podem fornecer subsídios para um monitoramento mais rigoroso de determinados pontos da bacia hidrográfica do rio Una.

O objetivo do presente trabalho foi determinar as atividades de lactato desidrogenase e de malato desidrogenase nas brânquias e no fígado de Astyanax bimaculatus (lambari), que vivem em diferentes locais na bacia hidrográfica do rio Una, para averiguar o seu potencial como biomarcadora de alteração ambiental nessa bacia.

\section{MATERIAIS E MÉTODOS}

\subsection{Material biológico e locais de coleta}

Os peixes lambari (Astyanax bimaculatus) foram coletados entre os meses de novembro de 2013 a fevereiro de 2014, em corpos d'água da bacia hidrográfica do rio Una, localizado no município de Taubaté, SP. Os pontos de coleta foram denominados p1, p2 e p3, sendo que p1 foi no rio Itaim $\left(23^{\circ} 01^{\prime} 38,3^{\prime \prime} \mathrm{S}, 45^{\circ} 30^{\prime} 31,6^{\prime \prime} \mathrm{O}\right)$; p2 foi em um córrego (valeta) localizado

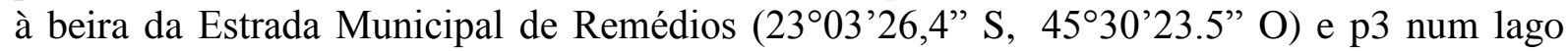
que é parte de um córrego sem nome, no trecho em que ele cruza com a Estrada Municipal Dr. José Luiz Cembranelli ( $23^{\circ} 01^{\prime} 49,4$ ' S, $45^{\circ} 30^{\prime} 16,7^{\prime \prime}$ O) (Figura 1). O rio Itaim encontra-se numa área de terraço, sujeita a inundações, mas esse rio é margeado, em grande parte, por áreas de mata ou capoeira e cercada de áreas com risco de erosão definido como medianamente estável/vulnerável. No entorno de trechos próximos a nascentes desse rio (longe do ponto de coleta), ocorrem áreas consideradas vulneráveis e moderadamente vulneráveis a erosão (ortofotos 2D, 2E e $2 \mathrm{~F}$ - uso da terra e vulnerabilidade, Banco de Dados Ambientais da Bacia do Rio Una - http://www.agro.unitau.br/una). Além disso, alguns trechos desse rio e alguns de seus afluentes estão próximos de área urbanizada. O local de coleta (p1) nesse rio esteve próximo à área cultivada do Departamento de Agronomia da Universidade de Taubaté. A valeta de p2 recebe água de drenagem de cultura de arroz. O p3 encontra-se numa área geológica de terraço, sujeita a inundações, cercada por área de pastagem (ortofoto $2 \mathrm{E}$ uso da terra e vulnerabilidade, Banco de Dados Ambientais da Bacia do Rio Una http://www.agro.unitau.br/una). 


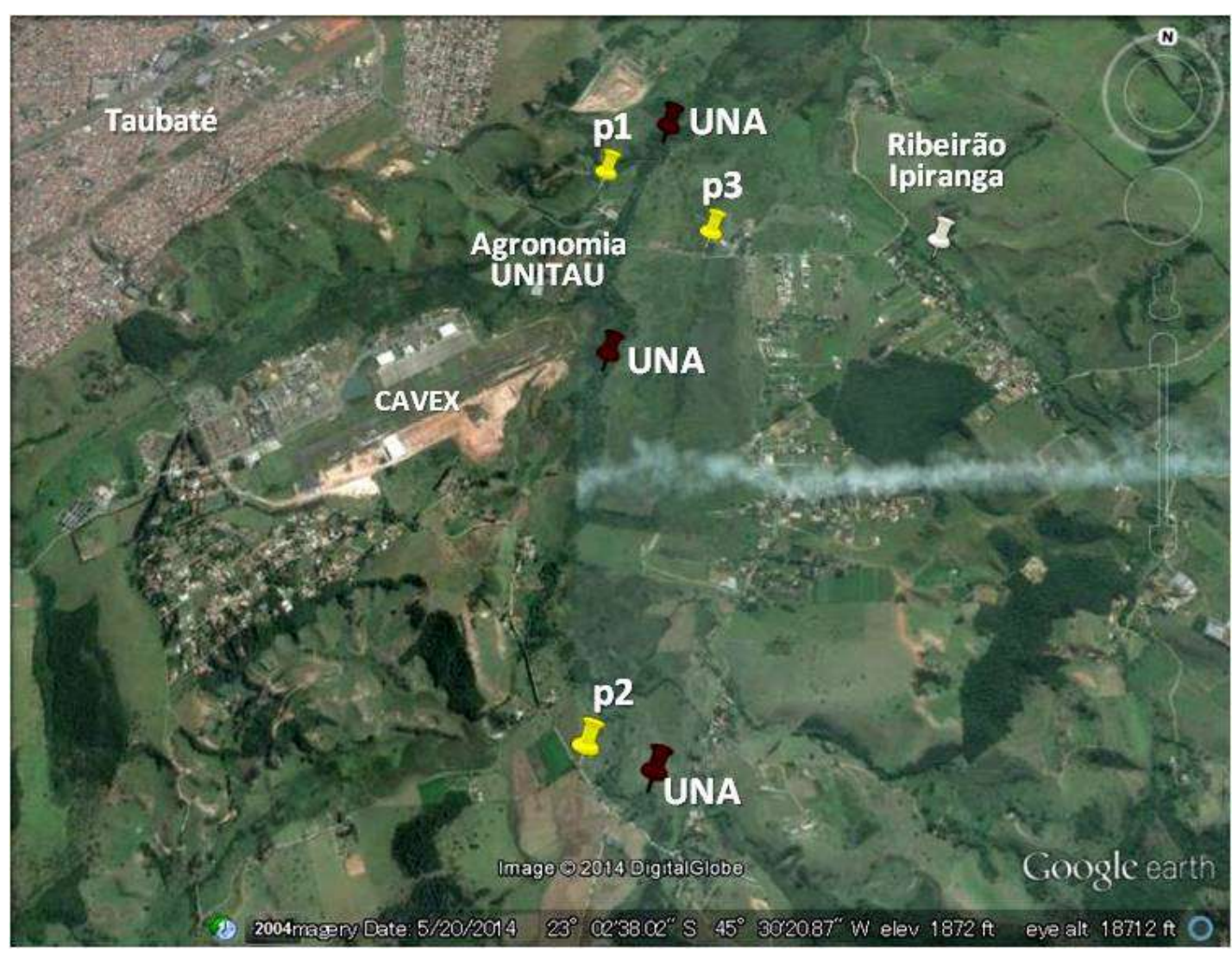

Figura 1. Imagem de satélite indicando os locais de amostragem (marcador amarelo), o rio Una e o ribeirão Ipiranga.

Fonte: Google Earth (2014).

Os peixes foram capturados com vara e anzol e/ou rede de pesca, anestesiados com benzocaína $(0,1 \%)$ dissolvida na água do rio, sacrificados por decaptação, dissecados, e as brânquias e o fígado foram mantidos em gelo e depois transportados para o laboratório de Bioquímica da Universidade de Taubaté. Os tecidos foram armazenados a $-86^{\circ} \mathrm{C}$ até o momento da utilização.

A captura dos peixes foi autorizada pelo Ministério do Meio Ambiente (SISBIO, $\mathrm{n}^{\mathrm{o}}$.41097-1) e pelo Comitê de Ética da Universidade de Taubaté (CEUA/UNITAU $\left.\mathrm{n}^{\mathrm{o}} .013 / 2013\right)$.

\subsection{Extração e determinação da atividade enzimática}

As brânquias ou o fígado de cada peixe foram homogeneizados separadamente com tampão Tris- $\mathrm{HCl} 50 \mathrm{mM}$, pH 7,4, na proporção de $5 \mathrm{ml}$ de tampão/g de tecido. $\mathrm{O}$ homogeneizado foi centrifugado a $10.000 \mathrm{rpm}$ (Eppendorf 5810R) durante 10 minutos, sendo o sobrenadante (extrato bruto) utilizado para determinação das atividades de LDH e MDH. A atividade de LDH foi determinada misturando-se piruvato de sódio $(1 \mathrm{mM}), \mathrm{KCl}(100 \mathrm{mM})$, tampão Tris-HCl $(50 \mathrm{mM}) \mathrm{pH} 7,4$ e NADH $(250 \mu \mathrm{M})$ a uma alíquota do extrato bruto de cada tecido (Thuesen et al., 2005). Para a atividade de MDH foram misturados ácido oxaloacético $(0,4 \mathrm{mM}), \mathrm{MgCl}_{2}(20 \mathrm{mM}), \mathrm{NADH}(150 \mu \mathrm{M})$ e tampão Tris-HCl $(50 \mathrm{mM}) \mathrm{pH}$ 7,4 ao extrato bruto (Childress e Somero, 1979). A taxa de oxidação de NADH na reação catalisada por essas enzimas foi determinada espectrofotometricamente (340 nm, Jenway $6715 \mathrm{UV} / \mathrm{Vis})$ e utilizada para cálculos de atividade, expressa em U.mg proteína ${ }^{-1}$.

O número de lambaris utilizados para determinação de cada uma dessas atividades encontra-se no Tabela 1. 
Tabela 1. Número de lambaris provenientes dos três pontos de coleta (p1, p2 e p3) dos quais foram utilizados o fígado e brânquias para dosagem de atividade de LDH e MDH.

\begin{tabular}{cccccc}
\hline \multirow{2}{*}{ Pontos de coleta } & \multicolumn{2}{c}{ Fígado } & & \multicolumn{2}{c}{ Brânquias } \\
\cline { 2 - 3 } \cline { 5 - 6 } & LDH & MDH & & LDH & MDH \\
\hline p1 & 7 & 5 & & 5 & 5 \\
p2 & 5 & 5 & & 5 & 5 \\
p3 & 4 & 5 & & 3 & 3 \\
\hline
\end{tabular}

\subsection{Dosagem de Proteínas}

A quantidade de proteínas em cada amostra foi determinada pelo método de Bradford (1976) utilizando-se albumina de soro bovino (BSA) como padrão.

\subsection{Análise Estatística}

Os resultados foram analisados através do teste de Kruskall-Wallis, pois as variâncias não foram semelhantes (teste de Bartlet) e alguns dados não apresentaram distribuição normal, segundo o teste de Kolmogorov-Smirnov. Esses testes foram executados com a utilização de um programa estatístico (GraphPad Prism version 5.00 for Windows, GraphPad Software, San Diego, Califórnia USA, <www.graphpad.com>). Outliers foram identificados pelo teste de Grubbs (www.graphpad.com/quickcalcs/grubbs) e foram excluídos das análises. O nível de significância $(\alpha)$ dos testes foi 0,05 .

\section{RESULTADOS E DISCUSSÃO}

Os lambaris utilizados no presente trabalho foram os mesmos utilizados para determinação das atividades das enzimas superóxido dismutase (SOD) e catalase (CAT), cujos resultados já foram publicados, bem como as análises da água dos locais de coleta desses peixes (Batista et al., 2014). Contudo, alguns resultados relevantes encontram-se na Tabela 2. Essas análises revelaram que a condutividade esteve elevada nos três pontos, particularmente em p2 (área agrícola).

A cor aparente esteve elevada em todos os pontos, especialmente em p3 (área de pastagem). Não existe um limite desse parâmetro para água de rios, mas valores entre 114 a $550 \mathrm{mg} \mathrm{Pt}-\mathrm{Co} / \mathrm{L}$ foram encontrados em um rio que recebe influência antrópica no Brasil (Carvalho e Queija de Siqueira, 2011), valores esses inferiores àquele verificado em p3. A cor aparente é influenciada pela turbidez e o aumento desta pode estar associado à presença de sólidos em suspensão, tais como partículas inorgânicas (areia, silte, argila) e de detritos orgânicos, além de algas, bactérias e plânctons em geral (Yuncong et al., 2011).

O valor da demanda Química do Oxigênio (DQO) foi acima dos padrões estabelecidos para águas superficiais, não poluídas, em p3, mas a resolução CONAMA 357 não estabelece um limite para esse parâmetro. DQO é um indicador da quantidade de matéria orgânica e inorgânica presente na água, baseado na determinação de oxigênio consumido para oxidar esses materiais, na presença de um oxidante forte (Chapman e Kimstach, 1996). Como p3 encontra-se numa área sujeita a inundações, cercada por área de pastagem, é possível que tenha ocorrido um carregamento de matéria orgânica dos pastos ao córrego, pois o período da coleta de água e de peixes coincidiu com período de chuvas. A erosão das margens dos rios em estações chuvosas pode resultar em aumento da turbidez. É possível que as chuvas ocorridas no período de coleta tenham também contribuído para a turbidez no p3, cujo valor esteve próximo ao limite superior de referência. 
Tabela 2. Parâmetros de qualidade da água em três pontos de coleta de lambaris (p1, p2 e p3) localizados na Bacia Hidrográfica do Rio Una. Reproduzido parcialmente de Batista et al. (2014).

\begin{tabular}{|c|c|c|c|c|}
\hline Parâmetros & $\mathrm{p} 1$ & $\mathrm{p} 2$ & p3 & $\begin{array}{l}\text { Limite superior de } \\
\text { referência }{ }^{\text {a }}\end{array}$ \\
\hline Condutividade $(\mu \mathrm{S} / \mathrm{cm})$ & 106,0 & 198,7 & 121,0 & $100^{b}$ \\
\hline Cor aparente $(\mathrm{mg} \mathrm{Pt}-\mathrm{Co} / \mathrm{L})$ & 307,0 & 191,5 & 858,0 & - \\
\hline Turbidez (NTU) & 30,9 & 22,7 & 101,0 & $100^{\mathrm{a}}$ \\
\hline $\mathrm{DQO}\left(\mathrm{mg} \mathrm{O}_{2} / \mathrm{L}\right)$ & 8,45 & 10,75 & 64,21 & $20^{\mathrm{c}}$ \\
\hline
\end{tabular}

${ }^{a}$ Limite estabelecido pela resolução CONAMA 357 (CONAMA, 2005) para rios de classe II, exceto para os casos de outro modo especificados, pois os limites dos demais parâmetros não constam nessa resolução.

${ }^{\mathrm{b}}$ Para águas superficiais não poluídas (CETESB, 2014).

${ }^{\mathrm{c}}$ Para águas superficiais não poluídas (Chapman e Kimstach,1996).

A atividade de MDH hepática (Figura 2A) foi aparentemente inferior nos lambaris coletados nos pontos 2 e 3 em comparação ao p1. Contudo, a diferença não foi estatisticamente significativa entre eles.

A atividade de MDH branquial foi inferior nos peixes coletados em p3 em comparação com aqueles coletados em p1 e p2 (Figura 2B). Entretanto, a atividade não diferiu estatisticamente entre os peixes coletados nos três pontos.
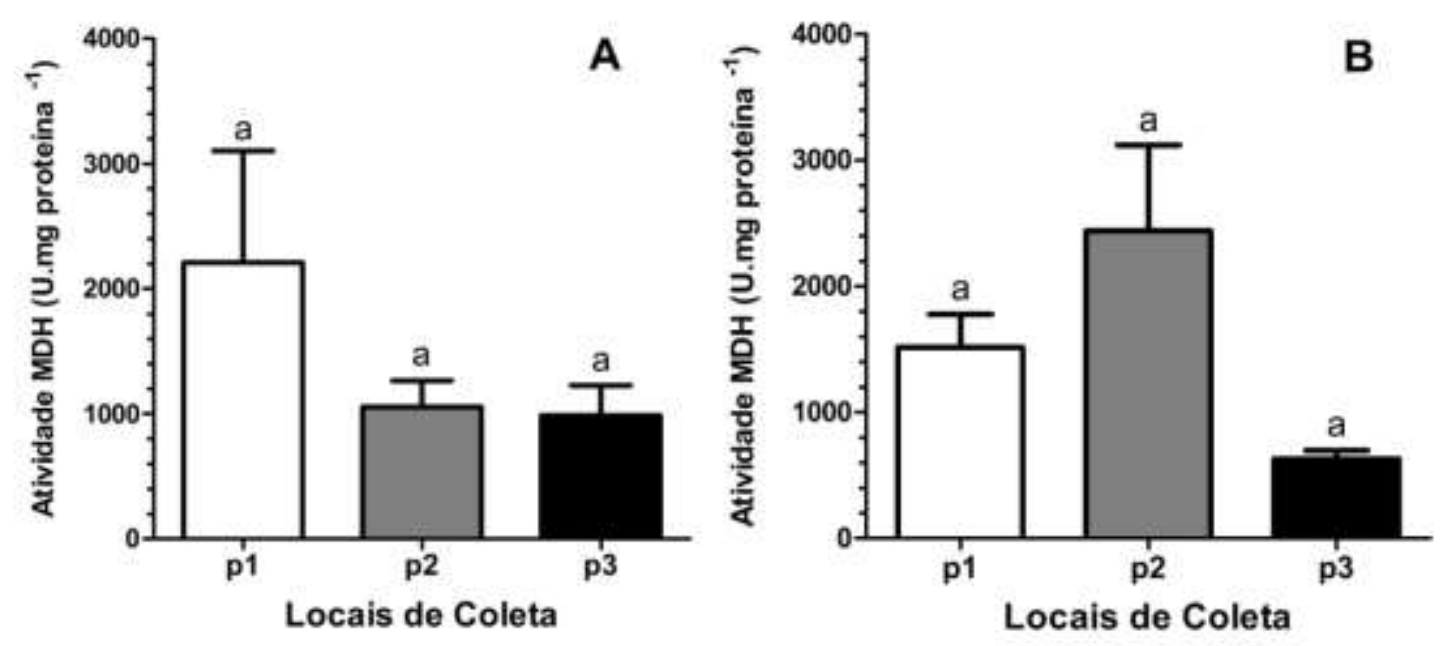

Figura 2. Atividade de MDH do fígado (A) e das brânquias (B) de A. bimaculatus coletados em três corpos d'água da bacia hidrográfica do rio Una. As barras de desvio indicam o erro-padrão da média. Letras iguais sobre as colunas indicam que a diferença não foi significativa entre os locais de coleta $(p<0,05)$.

A Figura 3A mostra que a atividade de LDH hepática foi menor nos peixes coletados em p2 e p3, localizados numa área agrícola e numa área de pastagem, respectivamente. A valeta de $\mathrm{p} 2$, de onde os lambaris foram coletados recebe água de drenagem da cultura de arroz. As chuvas e a drenagem podem ter carregado resíduos de defensivos agrícolas para a valeta de p2, afetando o metabolismo dos peixes desse local e inibindo LDH. Situação semelhante pode ter ocorrido em p3, aonde fezes de animais e matéria orgânica foram carregadas para o córrego. Entretanto, devido ao grande valor do desvio-padrão na amostra proveniente do ponto $\mathrm{p} 1$, a diferença não foi estatisticamente significativa entre os três locais de coleta. 
A atividade de LDH branquial dos lambaris coletados em $\mathrm{p} 3$ foi estatisticamente inferior à dos peixes coletados em p1 (Figura 3B). Mas, a atividade nos peixes em p2 não diferiu significativamente daquela dos lambaris coletados nos demais pontos.

A causa exata da inibição de LDH branquial nos lambaris provenientes de p3 é desconhecida. A enzima pode ter sua atividade alterada devido a fatores como nível de oxigenação da água e temperatura (Panepucci et al., 2000), não necessariamente devido a poluentes. Contudo, LDH sanguínea do peixe Catostomus commersoni foi inibida in vitro por sais contendo $\mathrm{Hg}^{2+}, \mathrm{Au}^{3+}, \mathrm{Ag}^{+}, \mathrm{Pt}^{4+}, \mathrm{Pd}^{2+} \mathrm{e} \mathrm{Cu}^{2+}$ (Christensen, 1972; Christensen et al., 1982). LDH branquial do peixe Carassius auratus gibelio foi inibida por $\mathrm{Cu}^{2+}(100 \mu \mathrm{g} / \mathrm{L}$ ou $250 \mu \mathrm{g} / \mathrm{L}$ ) após $24 \mathrm{~h}, 48 \mathrm{~h}$ e $72 \mathrm{~h}$ de exposicão do peixe (Teodorescu et al., 2012). No caso do outro peixe de água doce, Anabas scandens, as atividades de LDH hepática e renal aumentaram durante os primeiros 15 dias, mas diminuiram com 30 dias de exposição a $25 \mathrm{mg} / \mathrm{L}$ de $\mathrm{Cr}^{3+}$ e $^{6 r}{ }^{6+}$ (Venugopal e Reddy, 1992). Elevações graduais na atividade de LDH também foram verificadas no peixe Cirrhinus mrigala expostos a 1/10 da concentração letal média $\left(\mathrm{LC}_{50}\right)$ de $\mathrm{Cd}^{2+}, \mathrm{Pb}^{2+} \mathrm{e} \mathrm{Hg}^{2+}$ durante 45 dias (Reddy, 2012).


Figura 3. Atividade de LDH do fígado (A) e das brânquias (B) de A. bimaculatus coletados em três corpos d'água da bacia hidrográfica do rio Una. As barras de desvio indicam o erro-padrão da média. Letras iguais sobre as colunas indicam que a diferença não foi significativa entre os locais de coleta $(p<0,05)$.

Segundo Gorbatiuk (2013), via de regra, a conversão do metabolismo aeróbico para o anaeróbico é um dos critérios que indicam o desenvolvimento de patologias causadas por fatores exógenos, tais como pesticidas. Em alguns peixes a poluição por pesticidas aumenta inicialmente o metabolismo anaeróbico, com aumento da atividade de LDH, mas essa enzima é inibida com o aumento do tempo de exposição ao pesticida.

Segundo Moreira et. al (2010), a exposição durante 96 horas ao pesticida deltametrina elevou a atividade de LDH muscular no peixe Poecilia reticulata. Situação semelhante foi observada no peixe Carassius auratus exposto durante 10 dias ao herbicida butachlor, cuja atividade do LDH sanguínea aumentou (Xu et al., 2015). Entretanto, a atividade da LDH branquial foi diminuída em salmões do Atlântico (Salmo salar) expostos a hidrocarbonetos derivados de petróleo durante 4 dias, e, também no segundo dia após o retorno à água limpa (Gagnon e Holdway, 1999).

Embora as causas da baixa atividade de LDH branquial verificada em p3, no presente trabalho, não tenham sido determinadas, pode ser possível que esse fenômeno tenha ocorrido 
devido a condições ambientais adversas vivenciadas pelos lambaris capturados nesse ponto, pois a análise de água revelou que a cor aparente, turbidez e DQO estiveram elevados nesse ponto (Batista et al., 2014). Portanto, esses resultados indicaram piores condições nesse local em relação aos demais e corroboram a hipótese de que LDH branquial de lambaris pode ser sensível a poluentes presentes em $\mathrm{p} 3$.

As atividades de LDH e MDH do fígado e de $\mathrm{MDH}$ branquial não se mostraram suficientemente sensíveis para indicar a variação ambiental nos três pontos de coleta. Contudo, as atividades das enzimas da defesa antioxidantes hepáticas (SOD e CAT) foram determinadas nos mesmos peixes coletados nesses três locais, tendo sido verificado que essas atividades foram elevadas em p3 (Batista et al., 2014). Esses dados sugerem que a elevada atividade de SOD e CAT pode ter protegido esse tecido, de modo que alterações significativas de LDH e MDH não ocorreram no fígado.

Foi também relatado que as águas da bacia rio Una podem causar toxicidade crônica em seres vivos (Alves e Cobo, 2013). Considerando que a atividade de LDH pode ser afetada pela presença de metais e pesticidas, essa enzima não possui especificidade para indicar a presença de um contaminante específico. Apesar disso, ela pode ser útil na detecção precoce de alterações ambientais, pois pode restringir a análise de contaminantes da água para um determinado grupo de poluentes, como por exemplo metais. As águas do rio Una apresentam elevações de metais, principalmente na época de chuvas, no ponto de captação para abastecimento público. Nesse local, no mesmo período em que as coletas do presente trabalho foram realizadas, foi detectada elevação dos níveis de alumínio e ferro dissolvidos e de manganês total em relação aos valores de referência estabelecidos pela resolução CONAMA 357 de 17/03/2005. Em outros anos, houve também elevações de cobre e chumbo além dos limites estabelecidos (https://servicos.cetesb.sp.gov.br/infoaguas/). É ainda desconhecido se essas elevações ocorrem também nos demais corpos d'água da bacia do rio Una, como nos locais de coleta do presente trabalho. Entretanto, os nossos resultados sugerem a necessidade de uma análise mais cuidadosa da qualidade da água dessa bacia para a preservação do seu ecossistema aquático, cuja diversidade e quantidade de peixes têm diminuído progressivamente, segundo depoimentos de pescadores da região.

\section{CONCLUSÃO}

As atividades de LDH e MDH hepáticas e MDH branquial do lambari de rabo amarelo não foram relacionadas a diferenças qualitativas na água, proveniente de três localidades da bacia hidrográfica do rio Una. Entretanto, LDH branquial desse peixe foi inibida no ponto p3, numa localidade aonde a qualidade da água mostrou-se inferior aos demais. Portanto, essa enzima branquial possui potencial para utilização como marcador bioquímico de alteração ambiental.

\section{AGRADECIMENTOS}

Aos Srs. Antonio Cortez Filho, João Batista Moraes, Nilson do Carmo e Eduardo Galvão de Aguiar, membros da Fazenda Piloto (UNITAU), pelo apoio e auxílio na coleta de peixes, bem como ao Sr. Paulo Rony Batista, pescador (in memoriam). Ao biólogo Dalton Tavares Bressane Nielsen, ictiologista, pela identificação do lambari de rabo amarelo. Às técnicas Ana Paula Costa, do Departamento Ciências Agrárias (UNITAU), e à Simone Sano Russi de Rezende do Departamento Engenharia Civil (UNITAU) pela análise de água. Anne Caroline Ribeiro e Maria Tereza Oliveira Batista receberam as bolsas de iniciação científica PIC da Universidade de Taubaté (IBB_42_2013) e PIBIC/CNPq (IBB_23_2013), respectivamente. 


\section{REFERÊNCIAS}

ALMEIDA, J. A.; DINIZ, Y. S.; MARQUES, S. F. G.; FAINE, L. A.; RIBAS, B. O.; BURNEIKO, R. C. et al. The use of the oxidative stress responses as biomarkers in Nile tilapia (Oreochromis niloticus) exposed to in vivo cadmium contamination. Environment International, v. 27, n. 8, p. 673-679, 2002. http://dx.doi.org/10.1016/ S0160- 4120(01)00127-1

ALVES, T.; COBO, V. J. Bioindicador Ceriodaphnia dubia aplicado na avaliação ecotoxicológica da água da bacia hidrográfica do rio Una. Revista Ambiente \& Água, Taubaté, v. 8, p.168-182, 2013. Supl. http://dx.doi.org/10.4136/ambi-agua.1371

BASAGLIA, F. Some aspects of isozymes of lactate dehydrogenase, malate dehydrogenase and glucosephosphate isomerase in fish. Comparative Biochemistry and Physiology, v. 92B, n. 2, p. 213-226, 1989. http://dx.doi.org/10.1016/0305-0491(89)90269-1

BATISTA, M. T. O.; RODRIGUES JR, E. R.; FEIJÓ-OLIVEIRA, M.; RIBEIRO, A. C.; RODRIGUES, E.; SUDA, C. N. K. et al. Tissue levels of the antioxidant enzymes superoxide dismutase and catalase in fish Astyanax bimaculatus from the Una River Basin. Revista Ambiente \& Água, Taubaté, v. 9, n. 4, p. 621-631, 2014. http://dx.doi.org/10.4136/ambi-agua.1473

BRADFORD, M. M. A rapid and sensitive method for the quantitation of microgram quantities of protein utilizing the principle of protein-dye binding. Analytical Biochemistry, v. 72 , n. $1 / 2$, p. 248-254, 1976. http://dx.doi.org/10.1016/00032697(76)90527-3

CONSELHO NACIONAL DO MEIO AMBIENTE (Brasil). Resolução n. 357, de 17 de março de 2005. Disponível em: <http://www.mma.gov.br/port/conama/res/ res05/res35705.pdf> Acesso em: 14 set. 2014.

CARVALHO, G. L.; QUEIJA DE SIQUEIRA, E. Qualidade da água do Rio Meia Ponte no perímetro urbano do município de Goiânia - Goiás. Revista Eletrônica de Engenharia Civil, v. 2, n. 1, jul. 2011. http://dx.doi.org/10.1016/0003-2697(76)90527-3

COMPANHIA AMBIENTAL DO ESTADO DE SÃO PAULO - CETESB. Águas superficiais: variáveis de qualidade das águas. Disponível em http://aguasinteriores.cetesb.sp.gov.br/publicacoes-e-relatorios/. Acesso em: 14 set. 2014.

CHAPMAN, D.; KIMSTACH, V. Selection of water quality variables. In: D. Chapman (Ed.). Water quality assessment: a guide to the use of biota, sediments and water in environmental monitoring. Cambridge: UNESCO/WHO/UNEP, 1996. Disponível em: <http://www.who.int/water_sanitation_health/resources/wqa/en/>. Acesso em: 11 mar. 2014.

CHILDRESS, J. J.; SOMERO, G. N. Depth-related enzymic activities in muscle, brain and heart of deep-living pelagic marine teleosts. Marine Biology, v. 52, n. 3, p. 273-283, 1979. http://dx.doi.org/10.1007/BF00398141

CHRISTENSEN, G. M. Effects of metal cations and other chemicals upon the in vitro activity of two enzymes in the blood plasma of the white sucker, Catostomus commersoni (Lacepede). Chemico-Biological Interactions, Amsterdam, v. 4, n. 5, p. 351-361, 1972. http://dx.doi.org/10.1016/0009-2797(72)90089-0 
CHRISTENSEN, G. M.; OLSON, D.; RIEDEL, B. Chemical effects on the activity of eight enzymes: A review and a discussion relevant to environmental monitoring. Environmental Research, v. 29, n. 2, p. 247-255, 1982. http://dx.doi.org/10.1016/0013-9351(82)90026-3

DIAMANTINO, T. C.; ALMEIDA, E.; SOARES, A. M. V. M.; GUILHERMINO, L. Lactate dehydrogenase activity as an effect criterion in toxicity tests with Daphnia magna Straus. Chemosphere, v. 45, n. 4/5, p. 553-560, 2001. http://dx.doi.org/10.1016/S0045-6535(01)00029-7

GAGNON, M. M.; HOLDWAY, D. A. Metabolic enzyme activities in fish gills as biomarkers of exposure to petroleum hydrocarbons. Ecotoxicology and Environmental Safety, v. 44, n. 1, p. 92-99, 1999. http://dx.doi.org/10.1006/eesa.1999.1804

GORBATIUK, L. O. Energy supply of the fish organism under the impact of pesticides (a review). Hydrobiological Journal, v. 49, n. 1, p.79-90, 2013. http://dx.doi.org/10.1615/HydrobJ.v49.i1.80

HAYASHI, C.; MEURER, F. B.; BOSCOLO, W. R. R.; LACERDA, C. H. F.; KAVATA, L. C. C. S. B. Frequiência de arraçoamento para alevinos de lambari do rabo-amarelo (Astyanax bimaculatus). Revista Brasileira de Zootecnia, Viçosa, v. 33, n. 1, p. 21-26, 2004. http://dx.doi.org/10.1590/S1516-35982004000100004

MOREIRA, S. M.; MOREIRA-SANTOS, M.; RENDÓN-VON OSTEN, J.; DA SILVA, E. M.; RIBEIRO, R.; GUILHERMINO, L. et al. Ecotoxicological tools for the tropics: Sublethal assays with fish to evaluate edge-of-field pesticide runoff toxicity. Ecotoxicology and Environmental Safety, v. 73, n. 5, p. 893-899, 2010. http://dx.doi.org/10.1016/j.ecoenv.2010.04.007

PAUWELS, M.; FRÉROT, H.; SOULEMAN, D.; VANDENBULCKE, F. Using biomarkers in an evolutionary context: Lessons from the analysis of biological responses of oligochaete annelids to metal exposure. Environmental Pollution, v. 179, n. 0, p. 343350, 2013. http://dx.doi.org/10.1016/j.envpol.2013.05.005

PANEPUCCI, L.; FERNANDES, M. N.; SANCHES, J. R.; RANTIN, F. T. Changes in lactate dehydrogenase and malate dehydrogenase activities during hypoxia and after temperature acclimation in the armored fish, Rhinelepis strigosa (Siluriformes, Loricariidae). Revista Brasileira de Biologia, São Carlos, v. 60, n. 2, p. 353-360, 2000. http://dx.doi.org/10.1590/S0034-71082000000200021

REDDY, S. J. Impact of heavy metals on changes in metabolic biomarkers of carp fish, Cirrhinus mrigala. International Journal of Bioassays, v. 1, n. 12, p. 227-232, 2012.

SEDEÑO-DÍAZ, J. E.; LÓPEZ-LÓPEZ, E. Freshwater fish as sentinel organism: from the molecular to the population level, a review. In: TURKER, H. (Ed.). New advances and contributions to fish biology. Disponível em: <http://www.intechopen.com/ download/pdf/41566>. Acesso em: 31 out. 2014

SLATINSKÁ, I.; SMUTNÁ, M.; HAVELKOVÁ, M.; SVOBODOVÁ, Z. Biochemical markers of aquatic pollution in fish-glutathione S-transferase. Folia Veterinaria, Košice, v.52, n.3-4, p.129-134, 2008. 
TEODORESCU, D.; MUNTEANU, M. C.; STAICU, A. C. ; DINISCHIOTU, A. Changes in lactate dehydrogenase activity in Carassius auratus gibelio (L. Pysces) kidney, gills and intestine induced by acute exposure to copper. Romanian Biotechnological Letters, Bucharest, v. 17, n. 6, p. 7873-7880, 2012.

THUESEN, E. V.; MCCULLOUGH, K. D.; CHILDRESS, J. J. Metabolic enzyme activities in swimming muscle of medusae: is the scaling of glycolytic activity related to oxygen availability? Journal of the Marine Biological Association of the United Kingdom, v. 85, n. 03, p. 603-611, 2005. http://dx.doi.org/10.1017/S0025315405011537

VENUGOPAL, N. B. R. K.; REDDY, S. L. N. Nephrotoxic and hepatotoxic effects of trivalent and hexavalent chromium in a teleost fish Anabas scandens: enzymological and biochemical changes. Ecotoxicology and Environmental Safety, v. 24, n. 3, p. 287-293, 1992. http://dx.doi.org/10.1016/0147-6513(92)90004-M

XU, H.-D.; WANG, J.-S.; LI, M.-H.; LIU, Y.; CHEN, T.; JIA, A.-Q. 1H NMR based metabolomics approach to study the toxic effects of herbicide butachlor on goldfish (Carassius auratus). Aquatic Toxicology, v. 159, n. 0, p. 69-80, 2015. http://dx.doi.org/10.1016/j.aquatox.2014.11.020

YUNCONG, L.; RENUKA, R. M.; LENA, Q. M. Laboratory Analyses. In: LI, Y.; MIGLIACCIO, K. (Ed.). Water quality concepts, sampling, and analyses. Boca Raton: CRC Press, 2011. p.157-198. 